\title{
Focusing on variation: methods and applications of the concept of beta diversity in aquatic ecosystems
}

\author{
Focando na variação: métodos e aplicações do conceito \\ de diversidade beta em ecossistemas aquáticos
}

Adriano Sanches Melo ${ }^{1}$, Fabiana Schneck ${ }^{2}$, Luiz Ubiratan Hepp ${ }^{3}$,
Nadson Ressyé Simões ${ }^{4}$, Tadeu Siqueira ${ }^{1,5}$ and Luis Mauricio Bini ${ }^{1}$

${ }^{1}$ Departamento de Ecologia, Universidade Federal de Goiás - UFG, CP 131, CEP 74001-970, Goiânia, GO, Brazil

e-mail: asm.adrimelo@gmail.com; tsiqueira@rc.unesp.br; lmbini@gmail.com

${ }^{2}$ Departamento de Ecologia, Universidade Federal do Rio Grande do Sul - UFRGS,

CP 15007, CEP 91501-970, Porto Alegre, RS, Brazil

e-mail: fabiana.schneck@gmail.com

${ }^{3}$ Departamento de Ciências Biológicas, Universidade Regional Integrada do Alto Uruguai e das Missōes - URI, Av. Sete de Setembro, 1621, CEP 99700-000, Erechim, RS, Brazil

e-mail: 1.hepp@yahoo.com.br

${ }^{4}$ Núcleo de Pesquisas em Limnologia, Ictiologia e Aquicultura - NUPELIA,

Universidade Estadual de Maringá - UEM, Av. Colombo, 5790, CEP 87020-900, Maringá, PR, Brazil e-mail: nadsonressye@yahoo.com.br

${ }^{5}$ Departamento de Ecologia, Universidade Estadual Paulista Júlio de Mesquita Filho - UNESP, Av. 24-A, 1515, CEP 13506-900, Rio Claro, SP, Brazil

\begin{abstract}
Ecologists usually estimate means, but devote much less attention to variation. The study of variation is a key aspect to understand natural systems and to make predictions regarding them. In community ecology, most studies focus on local species diversity (alpha diversity), but only in recent decades have ecologists devoted proper attention to variation in community composition among sites (beta diversity). This is in spite of the fact that the first attempts to estimate beta diversity date back to the pioneering work by Koch and Whittaker in the 1950s. Progress in the last decade has been made in the development both of methods and of hypotheses about the origin and maintenance of variation in community composition. For instance, methods are available to partition total diversity in a region (gamma diversity), in a local component (alpha), and several beta diversities, each corresponding to one scale in a hierarchy. The popularization of the so-called raw-data approach (based on partial constrained ordination techniques) and the distance-based approach (based on correlation of dissimilarity/ distance matrices) have allowed many ecologists to address current hypotheses about beta diversity patterns. Overall, these hypotheses are based on niche and neutral theory, accounting for the relative roles of environmental and spatial processes (or a combination of them) in shaping metacommunities. Recent studies have addressed these issues on a variety of spatial and temporal scales, habitats and taxonomic groups. Moreover, life history and functional traits of species such as dispersal abilities and rarity have begun to be considered in studies of beta diversity. In this article we briefly review some of these new tools and approaches developed in recent years, and illustrate them by using case studies in aquatic ecosystems.
\end{abstract}

Keywords: temporal turnover, hierarchical scale, rare species, dissimilarity, CCA.

Resumo: Ecólogos geralmente estimam médias, mas dedicam pouca atenção à variação. O estudo da variação é um aspecto chave para entender sistemas naturais e fazer prediçôes. Em ecologia de comunidades, a maioria dos estudos foca na diversidade local de espécies (diversidade alfa), e apenas recentemente ecólogos passaram a dar atenção apropriada a variação na composição de comunidades entre sítios amostrais (diversidade beta). Isto acontece apesar do fato das primeiras tentativas de estimar diversidade beta terem sido feitas pelos trabalhos pioneiros de Koch e Whittaker na década de 1950. Houve significativo progresso na última década no desenvolvimento tanto de métodos como de hipóteses sobre a origem e manutenção da variação na composição de comunidades. Por exemplo, métodos estão disponíveis para particionar a diversidade total de uma região 
(diversidade gama) num componente local (alfa) e diversos componentes de diversidade beta, cada um referente a uma escala na hierarquia. A popularização da chamada abordagem de dados brutos (raw-data approach) (baseada em técnicas de ordenação parcial restrita) e abordagem baseada em distância (distance-based approach) (baseada em correlações de matrizes de dissimilaridade/distância) tem possibilitado a avaliação de hipóteses sobre os padróes de diversidade beta. De maneira geral, estas hipóteses são baseadas nas teorias de nicho e neutra, e levam em consideraçáo o papel do ambiente e do espaço (ou combinação deles) na determinação das metacomunidades. Estudos recentes avaliaram estes temas em grande variedade de escalas espaciais e temporais, de habitats e grupos taxonômicos. Adicionalmente, histórias de vida e traços funcionais das espécies tais como habilidades de dispersão e raridade estão começando a ser consideradas nos estudos de diversidade beta. Neste artigo nós revisamos brevemente algumas destas novas ferramentas e abordagens e as ilustramos com estudos de caso em ecossistemas aquáticos.

Palavras-chaves: substituição temporal, escalas hierarquicas, espécies raras, dissimilaridade, CCA.

\section{Introduction}

Most ecological studies aim to estimate means. For instance, many studies on population ecology estimate average population growth rate, while in community ecology it is very common to estimate the average number of species found in a particular type of habitat. The use of a measure of variability as a response variable is rare, particularly in aquatic ecology (Palmer et al., 1997), although recent studies have addressed this topic (Melo et al., 2009; Nabout et al., 2009; Ng et al., 2009; Heino et al., 2010). This lack of studies persists despite the fundamental cues that variability allows us to best understand natural ecosystems and consequently to design practical applications for management (Palmer and Poff, 1997).

In community ecology, a fundamental concept of variation is beta diversity, which can be defined simply as the variation in community composition among sites or among time periods (but see Tuomisto, 2010; Anderson et al., 2010). The concept is not new, and the first suggestions for its use and quantification were made by Koch (1957) and Whittaker (1960). However, the concept was rarely used until the end of the 1990s. Since then, the increasing interest of ecologists concomitantly with the development of new methods of study have made the subject a popular topic in ecology (Figure 1).

One of the first forms of quantification of beta diversity was the ratio of the regional species richness and the average species richness observed at the component sites (Koch, 1957; Whittaker, 1960), also known as hierarchical beta diversity. A second, related approach involves the use of dissimilarity indices (Koleff et al., 2003). More recently, methods have been generalized to take into account not only the local-regional scales but many hierarchical scales, such as additive or multiplicative diversity partitioning (Allan, 1975; Crist et al., 2003; Jost, 2007).

In addition to methods to estimate beta diversity, a new avenue has been opened by the availability of methods to study directly factors that generate beta diversity (Padial et al., 2010). Most of these new methods that relate environmental factors to beta diversity may be grouped in the raw-data and the distance-based approaches (Legendre et al., 2005; Tuomisto and Ruokolainen, 2006). The raw-data approach is based on partial constrained ordination techniques such as partial Canonical Correspondence Analysis (pCCA), partial Redundancy Analysis (pRDA) and partial Canonical Analysis of Principal Coordinates (pCAP). They are used to estimate the relative roles of environmental and spatial variables (or groups of variables) in accounting for variation in community composition (Legendre et al., 2005). The distance approach is based on correlation of dissimilarity/ distance matrices (partial Mantel, distance-based regression), and is aimed at identifying variables (or groups of variables) associated with variation in dissimilarity values (Melo et al., 2009).

The oldest and perhaps still the most popular focus of beta-diversity studies is the comparison of sites within a single region. For instance, many studies have evaluated the dissimilarity among nearby or distant sites (the distance-decay relationship; Nekola and White, 1999) and how representative a single site is of the region under study (the local-regional relationship; Loreau, 2000). In the last decade, however, the diversified set of tools to measure and explain beta diversity has stimulated studies on a wide array of subjects. 


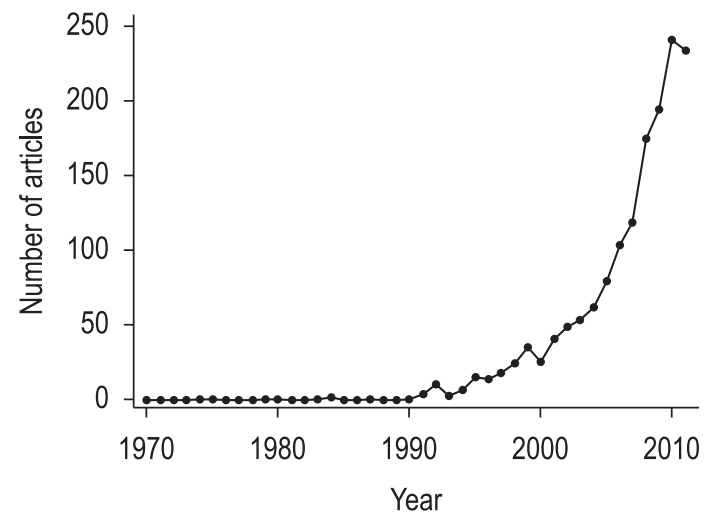

Figure 1. Number of articles indexed by the Institute for Scientific Information with the term "beta diversity" in the title or abstract in the period 1970-2011.

A popular extension of the beta-diversity concept observed in the last decade is diversity partitioning (Crist et al., 2003). The idea is to partition the total diversity and assess the relative importance of alpha (local) and several beta components, each one corresponding to a scale in a hierarchy. The most common approach is the use of additive partitioning of total species richness, although methods are available to carry out multiplicative partitioning and to use values of diversity indices rather than species richness (Jost, 2007). The magnitude of a particular component is dependent on the number and size of samples (or levels) on each scale, and is therefore not directly comparable. Accordingly, the importance of each component is usually contrasted to a distribution of expected values obtained under a null model (Crist et al., 2003; Ligeiro et al., 2010).

A second extension is the use of the beta diversity (or variation in community composition) across different temporal scales (Schneck et al., 2011). Studies on community variation in time (or persistence, stability) are not new, and have treated a wide array of organisms (Rahel, 1990; Vieira et al., 2005). However, recent studies have employed new tools that were originally developed to study space, to assess community variation over time. For instance, the alpha-beta relationship commonly used in the spatial dimension can be easily applied to the temporal dimension. Also, a relatively recent multivariate technique that measures beta diversity as the distance-to-centroid in a multidimensional space (Anderson et al., 2006) has been used to test a hypothesis of different community persistence in rainy or dry seasons on a multi-year scale (Schneck et al., 2011).

In addition to the new tools and the resultant widening in the scope of the studies (e.g., explanation or prediction of variation in community composition or dissimilarities among sites, partitioning of total diversity on multiple hierarchical scales, temporal dimension), a promising new focus of study is the relationship among life history and functional traits of species with beta-diversity patterns (Soininen et al., 2007). For instance, one may expect that groups of species with low dispersal ability would show high beta diversity in space when compared to groups with high dispersal abilities (Steinitz et al., 2006; Dobrovolski et al., 2012). Also, environmental and spatial processes generating beta diversity among sites for common species may differ from those determining beta diversity for rare species (Heino and Soininen, 2010; Siqueira et al., 2012).

In this article, we briefly review some of the new tools and approaches developed in recent years to study beta diversity. We illustrate these tools and different approaches using case studies in aquatic ecosystems. This article results from the Symposium "Beta diversity: theoretical and methodological advances" of the XIII Brazilian Meeting on Limnology held at Natal, Rio Grande do Norte in September 2011.

\section{How to Assess Factors that Generate Beta Diversity? The Raw- and Dissimilarity-Based Approaches}

\subsection{The data}

The basic dataset collected by ecologists who are interested in measuring and inferring the mechanisms behind beta diversity can be divided, at a minimum, into three tables. The first, the response variable matrix, consists of a communitycomposition data table or a sites-by-species matrix (Y). Environmental $(\mathbf{X})$ and spatial (W) sites-by-variables are the other two tables, which are often used as explanatory variable matrices within a metacommunity framework (Legendre, 2008). It is important to emphasize that a matrix containing spatial variables $(\mathbf{W})$ can be derived from an eigenfunction spatial analysis (Griffith and Peres-Neto, 2006 and references therein), a much more flexible approach than the use of simple geographical coordinates (latitude and longitude) or their polynomial extensions. Besides, simple geographical distance between two sites may be a poor representation of dispersal pathways or hydrological connections (e.g., streams in a river network), and therefore, spatial eigenfunction analyses can be applied to watercourse distances 
(e.g., Landeiro et al., 2011). Finally, even the direction of the flow may be allowed for by using eigenvector maps (AEM) modeling (Blanchet et al., 2008). In the case of the raw-data approach, the aforementioned rectangular matrices are used directly in constrained ordination analyses [e.g., redundancy analysis (RDA) and canonical correspondence analysis (CCA)]. For the distancebased approach, these matrices are transformed to triangular matrices using a suitable distance (or dissimilarity) index and are submitted to a Mantel test, for example.

\subsection{The objectives of raw-data and distance-based approaches}

Ecologists have used the raw-data and the distance-based approaches as equivalent methods to study beta diversity. However, Legendre et al. (2005) warned that distance-based methods should not be used to study beta diversity because variation in community composition may not translate into variation of dissimilarity values. They presented an example where sampling sites with different species compositions results in a dissimilarity matrix with all elements showing the same value. The criticism by Legendre et al. (2005) was followed by a paper by Tuomisto and Ruokolainen (2006) in which they argued that the two approaches are not equivalent (and thus not comparable), but should be used to test different ecological hypotheses. In their opinion, the raw-data approach should be used to study variation in community composition, whereas distance-based methods should be used to study variation in dissimilarity values. Tuomisto and Ruokolainen (2006, p. 2697) went further and suggested that:

"Hubbell's neutral theory could only be tested using the distance approach, because its testable predictions are stated in terms of distances, not in terms of raw data."

Their article stimulated an intense debate that was mainly composed of four articles: three commentaries on Tuomisto and Ruokolainen's article, by Legendre et al. (2008), Pélissier et al. (2008) and Laliberté (2008), and one reply to these comments by Tuomisto and Ruokolainen (2008). We suggest a careful reading of these articles for those who are interested in the study of beta diversity.

\subsection{The mechanisms}

Using these matrices and variation partitioning analyses (see below), the likelihoods that four main mechanisms will shape community structure are usually tested (e.g., Cottenie, 2005). These mechanisms include i) patch-dynamics, ii) speciessorting, iii) mass-effects and iv) neutral processes (Leibold et al., 2004). Of these, patch dynamics is rarely observed, at least in empirical studies (Logue et al., 2011), and will not be discussed here. The species-sorting mechanism or paradigm is probably the most familiar to aquatic ecologists, and assumes that species distributions are strongly controlled by environmental variation. Dispersal between sites (e.g., lakes) is supposedly not sufficient to erase the environmental signature. The neutral paradigm, on the other hand, assumes that species are ecologically equivalent in terms of birth, death and dispersal rates, and that dispersal limitation is the main process underlying variation in community composition. As a corollary, for instance, two lakes with similar environmental conditions may harbor communities with different compositions if the distance between them is large enough to reduce the homogenization effect caused by dispersal. Finally, according to the masseffects paradigm, both dispersal and niche-based processes are important in shaping the structure of local communities. For instance, two nearby lakes with different environmental characteristics may contain similar communities. Thus, although competitively dominant species are found in a lake where their environmental requirements are met, other species with different requirements may also be found in this lake due to their dispersal from other lakes that support the requirements of the second set of species. This source-sink dynamic tends to reduce the actual importance of environmental gradients as main predictors of community structure. However, these paradigms, which can act simultaneously on a metacommunity (Gonzalez, 2009), and consequently on the beta diversity, represent a gradation of the efficiency of local and regional processes in the determination of community structure. In general, to invoke these paradigms to explain beta diversity is to assume that the composition of a metacommunity is subject to local environmental conditions and/or demographic aspects, and environmental stochasticity (with caveats, see "the interpretation, the problems and, unfortunately, the few solutions" below).

\subsection{The analysis}

Armed with a set of empirical data (matrices $\mathbf{Y}$, $\mathbf{X}$ and $\mathbf{W}$ ), the relative roles of the metacommunity paradigms in shaping the structure of local communities may be quantified by a variation- 
partitioning analysis. This analytical tool was initially developed by Mood (1969) and popularized in the ecological literature by Borcard et al. (1992). Following a raw-data approach (Legendre et al., 2005), this analysis allows one to partition the total variation of $\mathbf{Y}$ into different fractions, as follows. The fractions $[a+b],[b+c]$ and $[a+b+c]$ correspond to the variation "explained" by the environmental data matrix $(\mathbf{X})$, by the spatial data matrix $(\mathbf{W})$, and by both sets of explanatory matrices (i.e., when the variables of both matrices are included in a single matrix), respectively. The fraction [d] is the variation that remained unexplained. In all cases, the composition data table $\mathbf{Y}$ is the response-variable matrix, and these fractions can be estimated by the adjusted canonical coefficients of determination $\left(R_{a d j}^{2}\right)$, a statistic that is not biased by the number of explanatory variables and sample size (Peres-Neto et al., 2006) derived from canonical analyses of $\mathbf{Y}$ with respect to $\mathbf{X}$, of $\mathbf{Y}$ with respect to $\mathbf{W}$, and of $\mathbf{Y}$ with respect to tables $\mathbf{X}$ and W, respectively (Legendre, 2008). There are three main canonical analyses that can be employed to partition the variability of raw data: partial Redundancy Analysis (pRDA), partial Canonical Correspondence Analysis (pCCA) and, used rarely, partial Constrained Principal Coordinates Analysis (pCAP). Thus, one needs to use one of these approaches and perform a total of three canonical analyses. Afterwards, the fractions of variation indicating the joint explanatory power of space and environment (fraction $\mathrm{b}$ - the spatially structured environmental variation), the variations explained exclusively by environmental predictors [a], and exclusively by the spatial variables [c] are estimated, respectively, by the following Equations 1, 2 e 3:

$$
\begin{aligned}
& {[\mathrm{b}]=[\mathrm{a}+\mathrm{b}]+[\mathrm{b}+\mathrm{c}]-[\mathrm{a}+\mathrm{b}+\mathrm{c}]} \\
& {[\mathrm{a}]=[\mathrm{a}+\mathrm{b}]-[\mathrm{b}]} \\
& {[\mathrm{c}]=[\mathrm{b}+\mathrm{c}]-[\mathrm{b}]}
\end{aligned}
$$

Fractions [a] and [c] can be tested for statistical significance using a Monte Carlo procedure (Legendre and Legendre, 1998; see pages 608612). Also, a bootstrap procedure for testing for the difference between fractions [a] and [c] in canonical variation partitioning is described by Peres-Neto et al. (2006).

The variation explained using the distance-based approach can be partitioned using the same general scheme presented above for the raw-data approach. However, in this case, variance partitioning is based on multiple regression of dissimilarity matrices (Lichstein, 2007) or Mantel and partial Mantel tests, instead of canonical analyses (pRDA, pCCA, or pCAP). However, some concern has been expressed about partitioning the variance of dissimilarity matrices (see Legendre et al., 2008); especially regarding the non-existence of a method to control for the number of variables in the estimation of the individual fractions (i.e., adjusted R-square); and whether the same amount of explained variation is obtained if all explanatory variables are included as a single distance matrix or as separate distance matrices (i.e., additivity). For the last concern, a single explanatory matrix constituted of physical and chemical variables could produce explained variation distinct from that produced by two matrices each one including physical or chemical variables.

\subsection{The interpretation, the problems and, unfortunately, the few solutions}

A common finding in studies partitioning variation among space and environment is that explained fractions are usually low (e.g. Landeiro et al., 2011). This could be simply a result of unmeasured environmental variables or use of inadequate spatial matrices. However, the solution in most cases is not easy. For instance, it is not always obvious which environmental variables affect biota and in what scale they should be measured. For the spatial matrix, it should reflect how organisms disperse within the landscape, what is not always obvious. For instance, distinct groups may present distinct dispersal forms and thus distinct spatial matrices would be necessary (Landeiro et al., 2011).

The magnitudes of fractions [a] and [c] are usually used to infer the relative importance of niche-based and neutral processes, respectively (e.g., Cottenie, 2005), while that of fraction [b] is equally consistent with either process. So far, so good. However, things are never that simple, and a number of caveats are associated with these interpretations despite the ever-increasing methodological advances in the field. First, a large fraction [c] may simply indicate the importance of a spatially autocorrelated environmental predictor missing from matrix $\mathbf{X}$ (Peres-Neto and Legendre, 2010). A possible solution to this conundrum consists in estimating species abundance according to a pure spatial model and testing the following predictions: i) estimated abundances are spatially structured in a similar way (this can be analyzed by a spatial correlogram), ii) estimated abundances are uncorrelated among each other and iii) the Mantel's 
correlation between matrices $\mathbf{M}$ (containing the similarity among the correlograms) and $\mathbf{R}$ (containing the correlations among abundances) should be non-significant (Diniz-Filho et al., 2012). Second, according to recent simulation studies, fractions [a] and [c] are not unequivocal indicators of the relative importance of niche and neutral processes in accounting for variation in the structure of local communities (see below) (Gilbert and Bennett, 2010; Smith and Lundholm, 2010).

In general, the same interpretations regarding the relative roles of niche and neutral processes are made when the fractions are estimated according to a distance approach (where matrices $\mathbf{Y}, \mathbf{X}$ and $\mathbf{W}$ are first converted to distances). However, the different questions targeted by the raw-data and distance approaches should be considered (Legendre et al., 2005, 2008; Tuomisto and Ruokolainen, 2006, 2008). We are of the opinion that the tests offered by the distance approach are more appropriate to assess the predictions of neutral theory (mainly the decrease in community similarity with distance; Hubbell, 2001). These tests, nevertheless, may also be flawed (Gilbert and Bennett, 2010). For instance, Smith and Lundholm (2010, p. 648) using simulations found that

"The degree of dispersal limitation contributes to

both the pure environmental and pure spatial variance partitions."

This a bit difficult to interpret as the straightforward expectation in this case would be an increase in the shared component [b]. The same authors found that

"[...] the proportion of variation attributed to environmental variation depends not only on the strength of environmental control, but also on the specific spatial configuration of the environmental variable." (Smith and Lundholm, 2010, p. 648).

In addition, Ferrier et al. (2007) indicated that non-linear relationships between compositional distance matrices derived from $\mathbf{Y}$ and $\mathbf{W}$ (or $\mathbf{X}$ ) distance matrices are commonly found. This nonlinearity, although its causes are simple (e.g., the upper limit of many dissimilarity coefficients used for biological, environmental and spatial data is 1), limits our ability to test metacommunity predictions. Although solutions to this problem exist (Ferrier et al., 2007), they are rarely (if ever) used.

\section{Where is Beta Diversity Highest? Beta Diversity at Multiple Spatial Scales}

Many processes and their resulting patterns in nature are scale-specific. For instance, biological interactions can be very important at a fine scale but not at intermediate or broad spatial scales. The importance of scale has been widely recognized, although only recently have ecologists studied it in detail (Wu and Loucks, 1995). In the context of beta diversity, ecologists may be interested in the variation in community composition among levels within a particular scale and among scales in a hierarchy. For instance, one may ask where the highest beta diversity resides in a range of hierarchical scales (e.g., microhabitat $[\mathrm{cm}] \rightarrow$ lake shore $[\mathrm{m}] \rightarrow$ lake $[\mathrm{km}] \rightarrow$ region $[10-100 \mathrm{~km}] \rightarrow$ biome [500-1000 km]).

Stream systems have a hierarchical structure composed of habitats (riffles, pools), stream segments, and the catchment basin (Allan, 2004). Aquatic assemblages vary on these different scales, and this variation can be caused by different factors. At small scales, variation should be caused mostly by the environment, while dispersal-related mechanisms should tend to be relatively more important at large scales (Parsons et al., 2003). Previous studies have suggested that for aquatic organisms, the proportion of variance explained by environmental factors increases with decreasing scale, whereas the spatial effects become more important at increasing scale (Mykrä et al., 2004). However, the correlation between environmental conditions and space make it difficult to determine the real importance of each one.

Hepp and Melo (unpublished manuscript) assessed the sole contribution of space in a range of hierarchical scales by sampling similar habitats of stream ecosystems. The field data included aquatic insects (Ephemeroptera, Plecoptera and Trichoptera) in 96 Surber sampling units in 48 riffles in 4 streams in 4 microbasins in southern Brazil. They evaluated the relative importance of alpha and beta diversity components at these multiple spatial scales using additive partitioning analysis of the total observed species richness. They showed that species richness at the scale of microhabitats (Surber units) was lower than that expected by an appropriate null model, indicating that the fauna is aggregated at this scale. A similar result has been obtained in previous studies, and seems to be a general feature of aquatic ecosystems (Stendera and Johnson, 2005; Ligeiro et al., 2010). On the other hand, the values of richness observed in the $\beta_{1}$ (among Surber), $\beta_{2}$ (among riffles), $\beta_{3}$ (among streams), and $\beta_{4}$ (among microbasins) were significantly higher than those expected under an appropriate null model. The highest absolute 
variation of the richness was found in $\beta_{3}$ (among streams, 30.6\%) and $\beta_{4}$ (among microbasins, $29.7 \%$ ). The beta-diversity component of the first scale ( $\beta_{1}=$ among Surbers) accounted for $7.9 \%$ of the total richness. They concluded that, taking into account the effect of environmental conditions, spatial effects are more pronounced at the upper levels of the hierarchy, that is, among streams and microbasins.

\section{Focusing on the Time Dimension: Interannual Beta Diversity}

Communities are temporally dynamic. This variability in community composition over time is equivalent to the variability in space, and thus can be termed temporal beta diversity or temporal turnover (Magurran, 2003; Korhonen et al., 2010). The analysis of temporal turnover contributes to the study of some intrinsic properties of communities, such as stability (Scarsbrook, 2002), resilience (Ives et al., 2003), resistance (Pimm, 1984) and persistence (Connell and Sousa, 1983). Also, they can produce insights on processes that ultimately determine community composition. For instance, Thomaz et al. (2007) showed that low beta diversity among water bodies is associated to seasonal floods that homogenize the biota. As the water level recedes, water bodies become isolated and the biota follow distinct temporal trajectories in part as a response to local factors, resulting in high beta diversity.

The degree of variability depends on a multitude of factors. For instance, temporal turnover is likely to be driven by environmental variability (Bengtsson et al., 1997), but it varies across ecosystems, organisms and latitude (Korhonen et al., 2010). Additionally, sampling artifacts can explain the variability of communities through time (Bengtsson et al., 1997), because of the occurrence of rare species in some samples but not in others. In this context, understanding which mechanisms are responsible for the temporal variability of communities is a challenge for ecologists. Although temporal turnover has received less attention than spatial turnover, recent studies with several aquatic communities have addressed this topic. For instance, studies on temporal turnover have focused on phytoplankton (Schneck et al., 2011), zooplankton (Shurin et al., 2007), macroinvertebrates (Milner et al., 2006; Siqueira et al., 2008), fish (Pyron et al., 2006) and aquatic macrophytes (Thomaz et al., 2009).
The study of temporal turnover can also have important applied implications, helping us to understand and identify the responses of ecological systems to natural and anthropogenic disturbances (Scarsbrook, 2002; Brown et al., 2006; Milner et al., 2006; Fraterrigo and Rusak, 2008). For instance, assessments considering only species diversity may not capture the effects of anthropogenic impacts, yet drastic changes may take place in species composition. In particular, native species may be replaced by exotic ones, although the alpha diversity at the site remains the same. Thus, the increase or decrease in beta diversity over time represents an additional way to assess whether, after a disturbance event, a community tends to diverge from or to converge with its original composition (Collins et al., 2000).

Recently, advances in analytical methods have allowed more accurate assessments of whether temporal dynamics differ among communities, ecosystems, or other groups of interest (Anderson et al., 2006), or whether temporal trends in beta diversity can lead to a convergence, divergence or stability of communities (Collins et al., 2000), and which mechanisms likely drive these trends (Clarke and Ainsworth, 1993). The method implemented by Anderson et al. (2006) uses a measure of variability (dispersion) within pre-defined groups of samples in a Principal Coordinates Analysis (PCoA). This procedure calculates the distance of each sampling unit to its group centroid in the multivariate space of a PCoA, followed by a permutation test that evaluates the null hypothesis that the groups did not differ in their dispersion (in a univariate context, this is similar to Levene's test of variance homogeneity). Thus, differences in the dispersion of the groups can be interpreted as differences in variability (i.e., beta diversity, persistence). Another interesting approach, which is closely based on the Mantel test, was developed by Collins et al. (2000), in which beta diversity is evaluated through increasing time lags. A regression analysis is applied between a dissimilarity matrix of the community (and thus a distance-based approach) and a time-lag matrix to evaluate temporal trends of the community. The slopes of the regressions indicate the rate of temporal change of the community (Korhonen et al., 2010). Direct assessments of the mechanisms related to temporal turnover of species can be performed using procedures for matrices comparisons. For example, the Mantel test correlates the temporal turnover of the community with a dissimilarity matrix of 
environmental variables (Legendre and Legendre, 1998). A similar procedure suggested by Clarke and Ainsworth (1993) optimizes the subset of environmental or spatial variables that best explain the matrix containing the pairwise compositional dissimilarities between sampling dates. Finally, the methods used to partition variation in community composition discussed previously (pCCA, pRDA and $\mathrm{pCAP}$ ) can also be extended to study time. In this case three matrices of explanatory variables are used (i.e., environmental, spatial and temporal sites-by-variables matrices) and, in addition to the exclusive fraction of each matrix, four other components are obtained reflecting the shared fractions among all three pairwise combinations and the fraction shared by all three factors.

A recent study used the distance-to-centroid approach to evaluate the interannual persistence of phytoplankton communities among summers (dry season) and among winters (rainy season) during five years in a subtropical reservoir (Schneck et al., 2011). The dispersion of the sampling units collected during rainy winters was significantly greater than the dispersion of the sampling units from summer, allowing the authors to conclude that assemblages occurring in the rainy season were less persistent (i.e., more variable) among years than were assemblages in the dry season. Additionally, the same approach was used to compare the environmental variability between the two seasons. The pattern observed was similar to that found for the community, with rainy winters showing greater environmental variability than summers among years. The study also found that the dissimilarity of the communities increased through time for both seasons, but was more pronounced among winters. These results support the view that greater environmental variability leads to greater variability (lower persistence) and greater dissimilarity of assemblages. Also, they imply that anthropogenic impacts should be best detected during dry seasons, when departures from reference conditions are minimal.

Alpha and gamma diversities may remain unchanged despite changes in community composition. Also, temporal trends of alpha and beta diversities may depend on the particular taxa under study. For instance, long-lived groups may show lower temporal beta diversity than those with short life spans. Bonecker et al. (unpublished manuscript) assessed alpha and beta diversity of zooplankton groups during a ten-year period (2000-2009) in the Upper Paraná River floodplain.
They observed that the diversity of testate amoebae increased over time, at both local and regional scales. In contrast, local and regional diversities of rotifers decreased over time, while microcrustaceans remained unchanged. Regarding beta diversity, there was a temporal trend of increase for both microcrustaceans and rotifers. They concluded that long-term changes in community composition were dependent on particular groups of organisms. Also, they showed the importance of taking beta diversity into account to best understand community dynamics.

\section{Focusing on Species: Beta Diversity in Sets of Common and Rare Species}

Recent advances in concepts and tools in the study of biodiversity patterns have stimulated the proposal of new hypotheses about the causes and consequences of beta diversity. For example, in their review of the distance decay of similarity in ecological communities, Soininen et al. (2007) extended the idea proposed by Nekola and White (1999) and suggested future studies to examine if variability in dispersal rates among organisms could affect the relationships between community dissimilarity and both geographic and environmental distance. Thus, in metacommunities composed of species that differ in their dispersal abilities, a different contribution of environmental variables and spatial processes to beta diversity patterns could be expected (Thompson and Townsend, 2006). In this context, Cottenie (2005) showed that the structure of metacommunities composed of a group of passively dispersed species is explained mainly by the environment, showing no significant sign of the effects of spatial processes.

More recently, some studies have begun to incorporate other species traits, such as mode of reproduction and the rarity and commonness of the constituent species, to best understand beta diversity patterns. One promising approach is to investigate whether beta diversity in sets of common and rare species (Chase et al., 2005) or of specialists and generalists (Pandit et al., 2009) is more likely to conform to the predictions of niche or neutral theory. Although recent research has suggested that species-richness patterns are driven mainly by common and widespread species (Jetz and Rahbek, 2002; Lennon et al., 2004), we know almost nothing about how sets of common and rare species contribute to beta-diversity patterns.

It is now becoming accepted in ecology that environmental and spatial processes do not act independently of each other, and that studies of 
beta diversity should consider simultaneously the roles of dispersal limitation and species' responses to environmental conditions (Leibold et al., 2004; Leibold and McPeek, 2006; Thompson and Townsend, 2006). Thus, one could hypothesize that common and rare species should be affected by deterministic and stochastic processes in different ways. This is because there is a close relationship between the main mechanisms proposed to explain commonness and rarity in nature, and current models proposed to explain beta diversity patterns in metacommunities. In general, the proposed determinants of rarity can be grouped into two broad categories. Some authors have suggested that deterministic processes related to niche differentiation among species cause some species to be rare and others to be common (Rabinowitz et al., 1984; Cornwell and Ackerly, 2010). For example, in an analysis of estuarine fish communities, Magurran and Henderson (2003) found that common and frequent species were associated with muddy substrata, whereas rare and occasional species were associated with rock, sand, gravel or weed substrata. Other authors have suggested that rarity is more related to stochastic processes related to dispersal limitation and colonization dynamics (Kunin and Gaston, 1993). For example, Resh et al. (2005) found that in long-term benthic-macroinvertebrate surveys, common species are more likely to disperse by drift and exhibit higher female dispersal potential than do rare species.

Two recent studies investigated the link between rarity and beta diversity in freshwater communities. Heino and Soininen (2010) and Siqueira et al. (2012) investigated the relationship between beta-diversity patterns, in sets of common and rare species, and environmental and spatial gradients. Whereas Heino and Soininen (2010) were interested in showing whether sets of common and rare species could be used to describe turnover-environment relationships shown by overall species sets, Siqueira et al. (2012) tested specific hypotheses about how common and rare species would be affected by environmental and spatial variables. These studies used a number of data sets on the distribution and abundance of phytoplankton, zooplankton, microcrustaceans and macroinvertebrates in ponds, lakes and streams from temperate and tropical regions. In summary, they obtained two main results. First, common species are the main drivers of beta diversity patterns in aquatic metacommunities, therefore suggesting that these patterns can be described using information from common species only (Heino and Soininen, 2010). The second result was that both common and rare species are affected mainly by similar environmental factors, but that rare species also respond to processes that operate at a more finegrained spatial scale, particularly biotic interactions (Siqueira et al., 2012). Besides providing clues about the causes of rarity in nature, these results show that a better understanding of beta diversity patterns can be reached if we consider metacommunities as composed of sets of species assembled by different ecological traits.

\section{The Decade of Beta Diversity: How Can We Advance? Time for an Epitaph?}

We mostly agree with Ricklefs' (2008, p. 741) criticisms of the weakness of studies on single local communities, and that studies focusing on regional scales

"[...] reveal more about the processes that generate diversity patterns than does the co-occurrence of species at any given point."

However, it should be noted that the enormous interest of ecologists in the local-regional relationship and beta diversity in the last decade has ameliorated the overall problem. In addition to the inclusion of multiple communities and broad spatial scales, we feel that little progress will be made until the problems with the use of the current available methods to model spatial variation in community structure have been solved.

Despite the indubitable conceptual and methodological advances seen in metacommunity ecology, we are far from reaching a general framework with high predictive power. Some authors consider that our goals should not consist of attempting to explain a large proportion of the variance in community structure (e.g., Ter Braak, 1986). However, despite using a plethora of methods, transformations and (environmental and spatial) predictors, it is difficult to be convincing about the mechanisms underlying species distribution when we usually explain, in general, only about $10 \%$ of the variance in the composition of species-rich communities. In these cases, a key issue is whether such a low percentage of explained variance is due to the lack of environmental or spatial variables or simply the stochastic nature of communities. Teasing apart these two sources of uncertainties is not easy, although experimental approaches are very promising (Chase, 2010). Also, it is harder to be persuaded, as is often attempted, that our results in the field can be of any help in slowing the ongoing 
loss of biodiversity. On the other hand, there are other paths that we can follow to avoid this. For instance, we still need more powerful multivariate or objective methods to delineate our response matrix, which are able to discriminate stochastic and noise variation. Perhaps we are being quixotic when we try to model the latter form of variation.

Most studies in emerging fields within ecology focus on documenting patterns. This is taken as a basis for inductive reasoning to pose mechanistic explanations a posteriori. Although this surely constitutes an important way in which science advances, it has some philosophical and practical shortcomings. For instance, many ecologists focus exclusively on gathering data to document patterns, as if this mountain of information could by itself reveal the hidden processes that generate the pattern (Rigler and Peters, 1995). Studies should be more theory-based and aim to test hypotheses and directional predictions. Most of the many experimental studies conducted up to now were designed to test a particular metacommunity paradigm (predominantly patch dynamics and mass-effects; see Logue et al., 2011). However, few studies have made specific predictions directly related to the dissimilarity values, although we envisage that these dissimilarity-based predictions should provide interesting insights in coming years. For instance, in a four-year experimental study with aquatic plants and animals, Chase (2010, p. 1388) has shown that higher compositional dissimilarity at higher productivity

"[...] resulted from a stronger role for stochastic relative to deterministic assembly processes with increasing productivity."

The increasing interest in beta diversity and the concurrent development of methods for its study seen in the last decade indicate that this field of study will be an actively investigated topic in ecology in the next decade. However, ecologists should take into account the challenges and difficulties (e.g., too-fine spatial scales, uncertainties regarding lack of predictor variables) to advance knowledge of beta diversity patterns and their generating processes.

\section{Acknowledgements}

We are grateful to A.F. Camargo for the invitation to write this article, and to J.L. Attayde and the Organizing Committee of the XIII Brazilian Meeting on Limnology, held at Natal, Rio Grande do Norte in September 2011, for the support offered to this symposium. Janet Reid reviewed the English. ASM received research grants
(476304/2007-5; 474560/2009-0; 558187/20099) and a research fellowship (302482/2008-3) from the Conselho Nacional de Desenvolvimento Científico e Tecnológico (CNPq). Research by LMB is continuously supported by CNPq. FS received a student fellowship from the Coordenação de Aperfeiçoamento de Pessoal de Nível Superior (CAPES). NRS and TS received postdoctoral fellowships from CNPq.

\section{References}

ALLAN, JD. 1975. Components of diversity. Oecologia, vol. 18, p. 359-367. http://dx.doi.org/10.1007/ BF00345855

ALLAN, JD. 2004. Landscape and Riverscapes: the influence of land use on stream ecosystems. Annual Review of Ecology, Evolution and Systematics, vol. 35, p. 257-284. http://dx.doi.org/10.1146/annurev. ecolsys.35.120202.110122

ANDERSON, MJ., CRIST, TO., CHASE, JM., VELLEND, M., INOUYE, BD., FREESTONE, AL., SANDERS, NJ., CORNELL, HV., COMITA, LS., DAVIES, KF., HARRISON, SP., KRAFT, NJB., STEGEN, JC. and SWENSON, NG. 2010. Navigating the multiple meanings of $\beta$ diversity: a roadmap for the practicing ecologist. Ecology Letters, vol. 14, no. 2, p. 19-28. PMid:21070562.

ANDERSON, MJ., ELLINGSEN, KE. and MCARDLE, BH. 2006. Multivariate dispersion as a measure of beta diversity. Ecology Letters, vol. 9, p. 683-693. PMid:16706913. http://dx.doi.org/10.1111/j.14610248.2006.00926.x

BENGTSSON, J., BAILLIE, SR. and LAWTON, J. 1997. Community variability increases with time. Oikos, vol. 78, p. 249-256. http://dx.doi. org/10.2307/3546291

BLANCHET, FG., LEGENDRE, P. and BORCARD, D. 2008. Modelling directional spatial processes in ecological data. Ecological Modelling, vol. 215, p. 325-336. http://dx.doi.org/10.1016/j. ecolmodel.2008.04.001

BONECKER, CC., SIMÓES, NR., MINTE-VERA, CV., LANSAC-TÔHA, FA., VELHO, LFM. and AGOSTINHO, AA. Temporal trends and relationships between zooplankton diversity components (gamma, beta, and alpha) in a long-term ecological research. Unpublished manuscript.

BORCARD, D., LEGENDRE, P. and DRAPEAU, P. 1992. Partialling out the spatial component of ecological variation. Ecology, vol. 73, p.1045-1055. http://dx.doi.org/10.2307/1940179

BROWN, L., MILNER, A. and HANNAH, D. 2006. Stability and persistence of alpine stream macroinvertebrate communities and the role of physicochemical habitat variables. Hydrobiologia, 
vol. 560, p. 159-173. http://dx.doi.org/10.1007/ s10750-005-1260-8

CHASE, JM. 2010. Stochastic community assembly causes higher biodiversity in more productive environments. Science, vol. 328, no. 5984, p. 13881391. http://dx.doi.org/10.1126/science. 1187820

CHASE, JM., AMARASEKARE, P., COTTENIE, K., GONZALEZ, A., HOLT, RD., HOLYOAK, M., HOOPES, MF., LEIBOLD, MA., LOREAU, M., MOUQUET, N.,SHURIN, JB. and TILMAN, D. 2005. Competing theories for competitive metacommunities. In HOLYOAK, M., LEIBOLD, MA. and HOLT, RD., eds. Metacommunities: Spatial Dynamics and Ecological Communities. Chicago: University of Chicago Press. p. 335-354.

CLARKE, KR. and AINSWORTH, M. 1993. A method of linking multivariate community structure to environmental variables. Marine Ecology Progress Series, vol. 92, p. 205-219. http://dx.doi.org/10.3354/ meps092205

COLLINS, SL., MICHELI, F. and HARTT, L. 2000. A method to determine rates and patterns of variability in ecological communities. Oikos, vol. 91, p. 285-293. http://dx.doi.org/10.1034/j.16000706.2000.910209.x

CONNELL, JH. and SOUSA, WP. 1983. On the evidence needed to judge ecological stability or persistence. The American Naturalist, vol. 121, p. 789823. http://dx.doi.org/10.1086/284105

CORNWELL, WK. and ACKERLY, DD. 2010. A link between plant traits and abundance: evidence from coastal California woody plants. Journal of Ecology, vol. 98, p. 814-821. http://dx.doi.org/10.1111/ j.1365-2745.2010.01662.x

COTTENIE, K. 2005. Integrating environmental and spatial processes in ecological community dynamics. Ecology Letters, vol. 8, no. 11, p. 1175-1182. PMid:21352441. http://dx.doi.org/10.1111/j.14610248.2005.00820.x

CRIST, TO., VEECH, JA., GERING, JC. and SUMMERVILLE, KS. 2003. Partitioning species diversity across landscapes and regions: a hierarchical analysis of $\alpha, \beta$, and $\gamma$ diversity. The American Naturalist, vol. 162, p. 734-743. PMid:14737711.

DINIZ-FILHO, JAF., SIQUEIRA, T., PADIAL, AA., RANGEL, TF., LANDEIRO, VL. and BINI, LM. 2012. Spatial autocorrelation analysis allows disentangling the balance between neutral and niche processes in metacommunities. Oikos, vol. 121, no. 2, p. 201-210. http://dx.doi.org/10.1111/j.16000706.2011.19563.x

DOBROVOLSKI, R., MELO, AS., CASSEMIRO, FAS and DINIZ-FILHO, JAF. 2012. Climatic history and dispersal ability explain the relative importance of turnover and nestedness components of beta diversity. Global Ecology and Biogeography, vol. 21, no. 2, p. 191-197. http://dx.doi.org/10.1111/j.14668238.2011.00671.x

FERRIER, S., MANION, G., ELITH, J. and RICHARDSON, K. 2007. Using generalized dissimilarity modelling to analyse and predict patterns of beta diversity in regional biodiversity assessment. Diversity and Distributions, vol. 13, no. 3, p. 252-264. PMid:18422637. http://dx.doi. org/10.1111/j.1472-4642.2007.00341.x

FRATERRIGO, JM. and RUSAK, JA. 2008. Disturbance-driven changes in the variability of ecological patterns and processes. Ecology Letters, vol. 11, p. 756-770. http://dx.doi.org/10.1111/ j.1461-0248.2008.01191.x

GILBERT, B. and BENNETT, JR. 2010. Partitioning variation in ecological communities: do the numbers add up? Journal of Applied Ecology, vol. 47, p. 1071-1082. http://dx.doi.org/10.1111/j.13652664.2010.01861.x

GONZALEZ, A. 2009. Metacommunities: Spatial Community Ecology. In John Wiley \& Sons, Ltd., ed. Encyclopedia of Life Sciences. Chichester: John Wiley \& Sons, Ltd. http://dx.doi. org/10.1002/9780470015902.a0021230

GRIFFITH, DA. and PERES-NETO, PR. 2006. Spatial modeling in ecology: the flexibility of eigenfunction spatial analyses in exploiting relative location information. Ecology, vol. 87, p. 2603-2613.

HEINO, J. and SOININEN, J. 2010. Are common species sufficient in describing turnover in aquatic metacommunities along environmental and spatial gradients? Limnology and Oceanography, vol. 55, p. 2397-2402. http://dx.doi.org/10.4319/ lo.2010.55.6.2397

HEINO, J., BINI, LM., KARJALAINEN, SM., MYKRÄ, H., SOININEN, J., VIEIRA, LCG. and DINIZ-FILHO, JAF. 2010. Geographical patterns of micro-organismal community structure: are diatoms ubiquitously distributed across boreal streams? Oikos, vol. 119, p. 129-137. http://dx.doi. org/10.1111/j.1600-0706.2009.17778.x

HEPP, LU. and MELO AS. Dissimilarity of stream insect assemblages: effects of multiple scales and spatial distances. Unpublished manuscript.

HUBBELL, SP. 2001. The unified neutral theory of biodiversity and biogeography. Princeton: Princeton University Press. 396 p.

IVES, AR., DENNIS, B., COTTINGHAM, KL. and CARPENTER, SR. 2003. Estimating community stability and ecological interactions from time-series data. Ecological Monographs, vol. 73, p. 301-330. PMid:12202829. http://dx.doi.org/10.1890/00129615(2003)073[0301:ECSAEI]2.0.CO;2

JETZ, W. and RAHBEK, C. 2002. Geographic range size and determinants of avian species richness. Science, 
vol. 297, p. 1548-1551. PMid:18027744. http:// dx.doi.org/10.1126/science.1072779

JOST, L. 2007. Partitioning diversity into independent alpha and beta components. Ecology, vol. 88, p. 2427-2439. http://dx.doi.org/10.1890/06-1736.1

KOCH, LF. 1957. Index of biotal dispersity. Ecology, vol. 38, p. 145-148.

KOLEFF, P., GASTON, KJ. and LENNON, JJ. 2003. Measuring beta diversity for presence absence data. Journal of Animal Ecology, vol. 72, p. 367-382. http:// dx.doi.org/10.1046/j.1365-2656.2003.00710.x

KORHONEN, JJ., SOININEN, J. and HILLEBRAND, H. 2010. A quantitative analysis of temporal turnover in aquatic species assemblages across ecosystems. Ecology, vol. 91, p. 508-517. PMid:20392015. http:// dx.doi.org/10.1890/09-0392.1

KUNIN, WE. and GASTON, KJ. 1993. The biology of rarity: patterns, causes and consequences. Trends in Ecology and Evolution, vol. 8, p. 298-301. http:// dx.doi.org/10.1016/0169-5347(93)90259-R

LALIBERTÉ, E. 2008. Analyzing or explaining beta diversity? Comment. Ecology, vol. 89, p. 3232-3237. http://dx.doi.org/10.1890/07-0201.1

LANDEIRO, VL., MAGNUSSON, WE., MELO, AS., ESPIRITO-SANTO, HMV. and BINI, LM. 2011. Spatial eigenfunction analyses in stream networks: do watercourse and overland distances produce different results? Freshwater Biology, vol. 56, p. 1184-1192. http://dx.doi.org/10.1111/j.13652427.2010.02563.x

LEGENDRE, P. 2008. Studying beta diversity: ecological variation partitioning by multiple regression and canonical analysis. Journal of Plant Ecology, vol. 1, p. 3-8. http://dx.doi.org/10.1093/jpe/rtm001

LEGENDRE, P. and LEGENDRE, L. 1998. Numerical Ecology. Amsterdam: Elsevier Science Ltd. 853 p.

LEGENDRE, P., BORCARD, D. and PERES-NETO, PR. 2005. Analyzing beta diversity: partitioning the spatial variation of community composition data. Ecological Monographs, vol. 75, p. 435-450. http:// dx.doi.org/10.1890/05-0549

LEGENDRE, P., BORCARD, D. and PERES-NETO, PR. 2008. Analyzing or explaining beta diversity? Comment. Ecology, vol. 89, p. 3238-3244. http:// dx.doi.org/10.1890/07-0272.1

LEIBOLD, MA., HOLYOAK, M., MOUQUET, N., AMARASEKARE, P., CHASE, JM., HOOPES, MF., HOLT, RD., SHURIN, JB., LAW, R., TILMAN, D., LOREAU, M. and GONZALEZ, A. 2004. The metacommunity concept: a framework for multiscale community ecology. Ecology Letters, vol. 7, p. 601-613. http://dx.doi.org/10.1111/j.14610248.2004.00608.x

LEIBOLD, MA. and McPEEK, MA. 2006. Coexistence of the niche and neutral perspectives in community ecology. Ecology, vol. 87, p. 1399-1410.
LENNON, JJ., KOLEFF, P., GREENWOOD, JJD. and GASTON, KJ. 2004. Contribution of rarity and commonness to patterns of species richness. Ecology Letters, vol. 7, p. 81-87. http://dx.doi. org/10.1046/j.1461-0248.2004.00548.x

LICHSTEIN, JW. 2007. Multiple regression on distance matrices: a multivariate spatial analysis tool. Plant Ecology, vol. 188, p. 117-131. http://dx.doi. org/10.1007/s11258-006-9126-3

LIGEIRO, R., MELO, AS. and CALLISTO, M. 2010. Spatial scale and the diversity of macroinvertebrates in a Neotropical catchment. Freshwater Biology, vol. 55, p. 424-435.

LOGUE, JB., MOUQUET, N., PETER, H. and HILLEBRAND, H. 2011. Empirical approaches to metacommunities: a review and comparison with theory. Trends in Ecology and Evolution, vol. 26, p. 482-491. http://dx.doi.org/10.1016/j. tree.2011.04.009

LOREAU, M. 2000. Are communities saturated? On the relationship between alpha, beta and gamma diversity. Ecology Letters, vol. 3, p. 73-76. http:// dx.doi.org/10.1046/j.1461-0248.2000.00127.x

MAGURRAN, AE. 2003. Measuring Biological Diversity. Oxford: Blackwell Science Ltd. 260 p.

MAGURRAN, AE. and HENDERSON, PA. 2003. Explaining the excess of rare species in natural species abundance distributions. Nature, vol. 422, p. 714-716.

MELO, AS., RANGEL, TFLVB. and DINIZ-FILHO, JAF. 2009. Environmental drivers of beta-diversity patterns in New-World birds and mammals. Ecography, vol. 32, no. 2, p. 226-236.

MILNER, A., CONN, S. and BROWN, L. 2006. Persistence and stability of macroinvertebrate communities in streams of Denali National Park, Alaska: implications for biological monitoring. Freshwater Biology, vol. 51, p. 373-387. http:// dx.doi.org/10.1111/j.1365-2427.2005.01488.x

MOOD, AM. 1969. Macro-analysis of the American educational system. Operations Research, vol. 17, p. 770-784. http://dx.doi.org/10.1287/opre.17.5.770

MYKRÄ, H., HEINO, J. and MUOTKA, T. 2004. Variability of lotic macroinvertebrate assemblages and stream habitat characteristics across hierarchical landscape classifications. Environmental Management, vol. 34, p. 341-352. PMid:15520891. http://dx.doi.org/10.1007/s00267-004-0236-1

NABOUT, JC., SIQUEIRA, T., BINI, LM. and NOGUEIRA, IS. 2009. No evidence for environmental and spatial processes in structuring phytoplankton communities. Acta Oecologica, vol. 35, p. 720-726. http://dx.doi.org/10.1016/j. actao.2009.07.002

NEKOLA, JC. and WHITE, PS. 1999. The distance decay of similarity in biogeography and ecology. 
Journal of Biogeography, vol. 26, p. 867-878. http:// dx.doi.org/10.1046/j.1365-2699.1999.00305.x

NG, ISY., CARR, CM. and COTTENIE, K. 2009. Hierarchical zooplankton metacommunities: distinguishing between high and limiting dispersal mechanisms. Hydrobiologia, vol. 619, p. 133-143. http://dx.doi.org/10.1007/s10750-008-9605-8

PADIAL, AA., BINI, LM., DINIZ-FILHO, JAF. and SOUZA, NPR. 2010. Predicting patterns of beta diversity in terrestrial vertebrates using physiographic classifications in the brazilian Cerrado. Natureza \& Conservaçáo, vol. 8, p. 127-132.

PALMER, MA., HAKENKAMP, CC. and NELSONBAKER, K. 1997. Ecological heterogeneity in streams: why variance matters. Journal of the North American Benthological Society, vol.16, p. 189-202. http://dx.doi.org/10.2307/1468251

PALMER, MA. and POFF, NL. 1997. The influence of environmental heterogeneity on patterns and processes in streams. Journal of the North American Benthological Society, vol. 16, p. 169-173. http:// dx.doi.org/10.2307/1468249

PANDIT, SN., KOLASA, J. and COTTENIE, K. 2009. Contrasts between habitat generalists and specialists: an empirical extension to the basic metacommunity framework. Ecology, vol. 90, p. 2253-2262. PMid:19739387. http://dx.doi.org/10.1890/080851.1

PARSONS, M., THOMS, MC. and NORRIS, RH. 2003. Scales of macroinvertebrate distribution in relation to the hierarchical organization of river systems. Journal of the North American Benthological Society, vol. 22, no. 1, p. 105-122. http://dx.doi.org/10.2307/1467981

PÉLISSIER, P., COUTERON, P. and DRAY, S. 2008. Analyzing or explaining beta diversity: comment. Ecology, vol. 89, p. 3227-3232. http://dx.doi. org/10.1890/07-0140.1

PERES-NETO, PR. and LEGENDRE, P. 2010. Estimating and controlling for spatial autocorrelation in the study of ecological communities. Global Ecology and Biogeography, vol. 19, p. 174-184. http:// dx.doi.org/10.1111/j.1466-8238.2009.00506.x

PERES-NETO, P., LEGENDRE, P., DRAY, S. and BORCARD, D. 2006. Variation partitioning of species data matrices: estimation and comparison of fractions. Ecology, vol. 87, p. 2614-2625. http:// dx.doi.org/10.1890/0012-9658(2006)87[2614:VP OSDM]2.0.CO;2

PIMM, SL. 1984. The complexity and stability of ecosystems. Nature, vol. 307, p. 321-326. http:// dx.doi.org/10.1038/307321a0

PYRON, M., LAUER, TE. and GAMMON, JR. 2006. Stability of the Wabash River fish assemblages from 1974 to 1998. Freshwater Biology, vol. 51, p. 1789-1797. http://dx.doi.org/10.1111/j.13652427.2006.01609.x

RABINOWITZ, D., RAPP, JK. and DIXON, PM. 1984. Competitive abilities of sparse grass species: means of persistence or cause of abundance. Ecology, vol. 65, no. 4, p. 1144-1154. http://dx.doi. org/10.2307/1938322

RAHEL, FJ. 1990. The hierarchical nature of community persistence: a problem of scale. The American Naturalist, vol. 136, p. 328-344. http://dx.doi. org/10.1086/285101

RESH, VH., BECHE, L. and MCELRAVY, EP. 2005. How common are rare species in long-term benthic macroinvertebrate studies? Journal of the North American Benthological Society, vol. 24, p. 976-989. http://dx.doi.org/10.1899/05-026.1

RICKLEFS, RE. 2008. Disintegration of the ecological community. The American Naturalist, vol. 172, no. 6, p. 741-750. PMid:18954264. http://dx.doi. org/10.1086/593002

RIGLER, FH. and PETERS, RH. 1995. Science and Limnology. Oldendorf: Ecology Institute. 239 p.

SCARSBROOK, M. 2002. Persistence and stability of lotic invertebrate communities in New Zealand. Freshwater Biology, vol. 47, p. 417-431. http://dx.doi. org/10.1046/j.1365-2427.2002.00810.x

SCHNECK, F., RODRIGUES, SC., SCHWARZBOLD, A. and MELO, AS. 2011. Environmental variability drives phytoplankton assemblage persistence in a subtropical reservoir. Austral Ecology, vol. 36, no. 7, p. 839-848. http://dx.doi.org/10.1111/j.14429993.2010.02224.x

SHURIN, JB., SHELLEY, EA., HILLEBRAND, H., LONGMUIR, A., PINEL-ALLOUL, B., WINDER, M. and YAN, ND. 2007. Diversitystability relationship varies with latitude in zooplankton. Ecology Letters, vol. 10, p. 127-134. PMid:17257100. http://dx.doi.org/10.1111/j.14610248.2006.01009.x

SIQUEIRA, T., ROQUE, FO. and TRIVINHOSTRIXINO, S. 2008. Phenological patterns of neotropical lotic chironomids: Is emergence constrained by environmental factors? Austral Ecology, vol. 33, p. 902-910. http://dx.doi.org/10.1111/ j.1442-9993.2008.01885.x

SIQUEIRA, T., BINI, LM., ROQUE, FO., COUCEIRO, SRM., TRIVINHO-STRIXINO, S. and COTTENIE, K. 2012. Common and rare species respond to similar niche processes in macroinvertebrate metacommunities. Ecography, vol. 35, p. 183-192. http://dx.doi.org/10.1111/ j.1600-0587.2011.06875.x

SMITH, TW. and LUNDHOLM, JT. 2010. Variation partitioning as a tool to distinguish between niche and neutral processes. Ecography, vol. 33, 
p. 648-655. http://dx.doi.org/10.1111/j.16000587.2009.06105.x

SOININEN, J., MCDONALD, R. and HILLEBRAND, H. 2007. The distance decay of similarity in ecological communities. Ecography, vol. 30, p. 3-12.

STEINITZ, O., HELLER, J., TSOAR, A., ROTEM, D. and KADMON, R. 2006. Environment, dispersal and patterns of species similarity. Journal of Biogeography, vol. 33, p. 1044-1054. http://dx.doi. org/10.1111/j.1365-2699.2006.01473.x

STENDERA, SS. and JOHNSON, RK. 2005. Additive partitioning of aquatic invertebrate species diversity across multiple spatial scales. Freshwater Biology, vol. 50, p. 1360-1375. http://dx.doi.org/10.1111/ j.1365-2427.2005.01403.x

TER BRAAK, CJF. 1986. Canonical correspondence analysis: a new eigenvector method for multivariate direct gradient analysis. Ecology, vol. 67, p. 11671179. http://dx.doi.org/10.2307/1938672

THOMAZ, SM., BINI, LM., and BOZELLI, RL. 2007. Floods increase similarity among aquatic habitats in river-floodplain systems. Hydrobiologia, vol. 579, p. 1-13. http://dx.doi.org/10.1007/s10750-0060285-y

THOMAZ, SM., CARVALHO, P., PADIAL, AA. and KOBAYASHI, JT. 2009. Temporal and spatial patterns of aquatic macrophyte diversity in the Upper Paraná River floodplain. Brazilian Journal of Biology, vol. 69, p. 617-625. PMid:19738968.

THOMPSON, RM. and TOWNSEND, CR. 2006. A truce with neutral theory: local deterministic factors, species traits and dispersal limitation together determine patterns of diversity in stream invertebrates. Journal of Animal Ecology, vol. 75, p. 476-484. http://dx.doi.org/10.1111/j.13652656.2006.01068.x

TUOMISTO, H. 2010. A diversity of beta diversities: straightening up a concept gone awry. Part 1. Defining beta diversity as a function of alpha and gamma diversity. Ecography, vol. 33, p. 2-22.

TUOMISTO, H. and RUOKOLAINEN, K. 2006. Analyzing or explaining beta diversity? Understanding the targets of different methods of analysis. Ecology, vol. 87, p. 2697-2708. http://dx.doi.org/10.1111/ j.1600-0587.2009.05880.x

TUOMISTO, H. and RUOKOLAINEN, K. 2008. Analyzing or explaining beta diversity? Reply. Ecology, vol. 89, p. 3244-3256. http://dx.doi. org/10.1890/0012-9658(2006)87[2697:AOEBD $\mathrm{U}] 2.0 . \mathrm{CO} ; 2$

VIEIRA, LCG., MARQUES, GS. and BINI, LM. 2005. Estabilidade e persistência de assembléias zooplanctônicas em um pequeno lago tropical. Acta Scientiarum, vol. 27, p. 323-328.

WHITTAKER, RH. 1960. Vegetation of the Siskiyou Mountains, Oregon and California. Ecological Monographs, vol. 30, p. 279-338. http://dx.doi. org/10.2307/1943563

WU, J. and LOUCKS, OL. 1995. From balance of nature to hierarchical patch dynamics: a paradigm shift in ecology. The Quarterly Review of Biology, vol. 70, no. 4, p. 439-466. http://dx.doi.org/10.1086/419172

Received: 03 October 2011 Accepted: 29 February 2012 